\title{
Effect of organic corrosion inhibitors on the crack growth rate in pipe steel X70 in a weakly acidic solution
}

\author{
V.E. Ignatenko, ${ }^{1}$ Vo Tyen, ${ }^{2}$ A.I. Marshakov, ${ }^{1}$ Yu.I. Kuznetsov, ${ }^{1}$ \\ N.N.Andreev, ${ }^{1}$ A.V. Muradov $^{2}$ and I.V. Ryakhovskikh ${ }^{3}$
}

${ }^{I}$ A.N. Frumkin Institute of Physical Chemistry and Electrochemistry, Russian Academy of Sciences, Leninsky pr. 31, 119071 Moscow, Russian Federation

${ }^{2}$ Gubkin Russian State University of Oil and Gas, Leninsky pr. 65, Moscow, 119991

Russian Federation

${ }^{3}$ Institute of Natural Gases and Gas Technologies - Gazprom VNIIGAZ LLC, Moscow

Oblast, Razvilka settlement, 142717 Russia Russian Federation

E-mail:mar@ipc.rssi.ru

\begin{abstract}
The effect of a number of organic corrosion inhibitors (CIs) on the growth rate of a corrosion crack in pipe steel X70 in a weakly acidic (pH 5.5) citrate buffer solution in the absence and in the presence of $1 \mathrm{mM} \mathrm{Na}_{2} \mathrm{~S}$ has been studied. A static straining load was applied to the specimens, with the stress intensity factor in the crack tip corresponding to the plateau of the kinetic curve of steel X70 destruction. The crack growth rate was determined from the change in the electric resistance of a specimen. The hydrogen penetration rate into metal was determined using the hydrogen electrochemical desorption method. It has been shown that CIs can considerably slow down the corrosion crack growth. In the solution containing no sulfide ions, the best protective properties are shown by IFKhAN-P-3 inhibitor (based on a salt of polyoxometalates with amines) and by a mixture of this inhibitor with phosphate (IFKhAN-P8). In the presence of sulfide ions, the best inhibitors of stress corrosion cracking (SCC) of pipe steel include the IFKhAN-P-3 and IFKhAN-P-8 formulations, as well as modifications of the IFKhAN-29 inhibitor and a quaternary ammonium compound, Catamin AB. Good correlation is observed between the corrosion crack growth rate and the anodic dissolution rate of mild steel in electrolytes containing corrosion inhibitors. Only a poor correlation is observed between the crack growth rate and the rate of hydrogen penetration into the metal; the existence of this relationship is apparently due to the fact that all the CIs studied slow down not only the anodic dissolution of steel but also the penetration of hydrogen into the metal. The conclusion has been made that local anodic dissolution of the metal is the predominant mechanism of the growth of corrosion cracks in pipe steel in weakly acidic electrolytes. The ability of organic compounds to inhibit SCC can be estimated by the anodic current density at constant potential selected in the region of active dissolution of mild steel.
\end{abstract}

Key words: stress corrosion cracking, pipe steel, resistometric method, corrosion inhibitors. 


\section{Introduction}

Stress corrosion cracking (SCC), also known as stress corrosion, is the most hazardous type of underground corrosion in high-pressure pipelines. It has been shown that the SCC of pipe steels is an electrochemical process, hence the rates of partial electrode reactions that occur on a corroding steel surface are among the main factors determining the crack initiation and growth $[1,2]$. Stress corrosion cracks on the external pipe surface appear under delaminated insulation coatings [1-5], hence electrochemical protection of pipelines cannot prevent the initiation and growth of SCC defects. Furthermore, detection and identification of the majority of these defects using automated tools for non-destructive monitoring of pipes during re-insulation are insufficiently reliable [6], and pipes with shallow SCC defects may remain in operation after a maintenance. Hence, there is a need to find new methods to combat this dangerous phenomenon.

Corrosion inhibitors (CIs) are compounds that can considerably decrease the corrosion rate of metals, up to complete corrosion prevention, without modifying the concentration of corrosive agents in the medium. The efficiency of CIs has been confirmed by long-term usage in various industries where metal structures, constructions and devices are operated [7]. Moreover, the use of CIs is the most practical and cost-effective method for reducing the corrosion losses of a metal in comparison with other anti-corrosion methods used in practice. The use of CIs in pipeline transport is generally aimed at decreasing the rate of internal corrosion in field pipelines [8]. It was suggested to use inhibitors for the preservation of stress corrosion defects in those cases where the pipe repair procedure does not guarantee that the electrolyte will be totally removed from the crack cavities and that they will not grow if the integrity of pipeline coating is violated in prolonged operation [6].

The literature sources that we examined revealed almost no data on the effect of corrosion inhibitors on the crack resistance of pipe steels with X70 strength class in weakly acidic soil electrolytes. The general principles of the inhibition of steel SCC in soil electrolytes, mostly in weakly alkaline carbonate-bicarbonate solutions, were determined $[9,10]$. Of the known inorganic CIs studied as SCC inhibitors for carbon and low-alloy steels in various corrosion media, chromates [11-14], nitrites [15-17], phosphates [10, 18-21], molybdates [22, 23] and borates [24-26] are worthy of note. However, no unambiguous effect of these compounds on the SCC of steels is observed, and they can even promote this process in some cases.

Among organic CIs, amines and quaternary ammonium compounds should be mentioned in the first place. They are often used as active components of inhibitors against hydrogen charging and acid corrosion of steels [27]. For example, Catamin AB (a quaternary ammonium compound) [28] has a high protective effect for steel in media containing hydrogen sulfide. This, along with its capability to preferentially inhibit the anodic partial reaction on a metal, allows one to make the conclusion that it is principally possible to use inhibitors of this type to protect pipe steels from SCC in soil electrolytes 
[29]. A number of other known organic inhibitors of SCC (imidazolines and formulations on their basis, hexamethylenetetramine and the product of its condensation with benzylamine) $[30,31]$ lack the required protective capability. It has not yet been studied whether known CIs based on salts of carboxylic acids and their mixtures with amines can be used to prevent or hinder the SCC of pipe steels.

It appears necessary to study the effect of corrosion inhibitors that belong to various classes of organic compounds on the SCC of pipe steels in weakly acidic electrolytes. The reagents we chose as such CIs are surfactants of cationic type (Catamin $\mathrm{AB}$ ), anionic type (AKN), salts of polyoxometallates with amines (IFKhAN-P-3 and IFKhAN-P-8), as well as products obtained by modification of IFKhAN-29 [32], a known corrosion inhibitor that consists of reaction products of fatty amines with various mixtures of higher unsaturated carboxylic acids modified by special additives. The purpose of IFKhAN-29 modifications was to perfect the technology and optimize the raw materials base for its synthesis. It should be noted that the success of protection is determined by a correct and reasonable selection of a CI with consideration for its chemical nature and mechanism of its impact on the kinetics of electrochemical reactions and composition of the corrosive medium.

It is well known that CIs of various classes hinder the anodic dissolution of steel or cathodic processes (including cathodic hydrogen evolution and hydrogen penetration into a metal). Most often, they hinder both the anodic and cathodic partial electrode reactions [30]. However, the SCC mechanism for pipe steels in pH-neutral and weakly acidic soil electrolytes remains a matter of discussion [1-5]. Some contributors believe that the SCC of pipe steels originates from hydrogen absorption by the metal [1]. Many researchers agree that the SCC of pipe steels in corrosive environments with near-neutral $\mathrm{pH}$ values results from a synergistic effect of local anodic dissolution of the metal and hydrogen absorption [2]. It has been shown that the effects of electrolyte components on the crack growth rate agree reasonably well with their stimulating or inhibitive action on the anodic dissolution of pipe steel [33]. Hence, to understand the mechanism of the protective effect of inhibitors on steel SCC, one first needs to study their effect on the kinetics of partial corrosion reactions, whereas the electrochemical behavior of pipe steels in inhibited media simulating the soil electrolyte has clearly been studied insufficiently.

The purpose of this study was to reveal the effect of corrosion inhibitors belonging to various classes of organic compounds on the growth rate of a crack in pipe steel X70 in weakly acidic ( $\mathrm{pH}$ 5.5) citrate buffer solution. This solution was already used before in studies of the SCC of pipe steels as a corrosive medium simulating a weakly acidic soil electrolyte, and it was shown that under static mechanical strain, a corrosion crack grew in a transgranular manner [33-35].

\section{Experimental}

The crack growth rate (CGR) was determined using $1420 \times 18.7 \mathrm{~mm}$ specimens of X70 strength class pipe steel cut from a pipe manufactured at Khartsyzsk Pipe Plant Co., Ukraine. The chemical composition of the steel is provided elsewhere [33]. 
Specimens with dimensions of $200 \times 17 \times 3 \mathrm{~mm}$ were cut from a pipe along its axial line at a distance of $120 \mathrm{~mm}$ from the longitudinal weld. Preliminarily, triangular stress concentrators $3 \mathrm{~mm}$ deep were cut in the specimens. After that, fatigue cracks $c a .5 \mathrm{~mm}$ deep were grown in the specimens to serve as crack growth initiators in the corrosion experiments. The specimens with cracks were fastened in three-electrode electrochemical cells that were then filled with an electrolyte being studied.

A static tensile mechanical load was applied to the specimens. The stress intensity factor at the crevice tip $K\left(\mathrm{MPa} \cdot \mathrm{m}^{0.5}\right)$ was calculated according to [36] using the expression for beam specimens with an end-to-end edge crack:

$$
K=\frac{P}{t \cdot \sqrt{b}} \cdot\left[\sqrt{\frac{l}{\left(1-\frac{l}{b}\right)^{3} \cdot b}} \cdot\left(1.941-1.741 \cdot\left(\frac{l}{b}\right)+4.07 \cdot\left(\frac{l}{b}\right)^{2}-2.528 \cdot\left(\frac{l}{b}\right)^{3}\right],\right.
$$

where $P$ is the load applied to the specimen; $l$ is the crack length; $b$ and $t$ are the specimen width and thickness, respectively. The $K$ value was chosen on the plateau of the kinetic curve of X70 steel destruction, i.e., the plot of the crack growth rate versus $K[34,35]$.

The crack growth rate $(V)$ was determined from the slope of the plot of electric resistance of specimens $\left(R_{\mathrm{cr}}\right)$ vs. time $(\tau)$ :

$$
V=l_{0}\left(R_{\mathrm{cr}} / R_{0}-1\right) / \tau
$$

where $R_{0}$ is the initial specimen resistance and $l_{0}$ is the initial crack length. The $R_{\mathrm{cr}}$ value was determined with consideration for the variation of the specimen temperature during the experiment. To do so, the current electric resistance values of the specimen parts with $(R)$ and without a crack $\left(R_{\mathrm{wo} / \mathrm{cr}}\right)$ were compared and $R_{\mathrm{cr}}$ was calculated as:

$$
R_{\mathrm{cr}}=R \cdot R_{\mathrm{wo} / \mathrm{cr}} / R_{0, \mathrm{wo} / \mathrm{cr}}
$$

where $R_{0, \text { wo/cr }}$ is the initial resistance of the specimen part without a crack. The specimen resistances were measured to within $10^{-8} \mathrm{Ohm}$ using a BSZ-100-002 microhmmeter.

Electrochemical measurements were carried out in a Devanathan-Stachurski cell [37] using foil membranes (08kp steel), $100 \mu \mathrm{m}$ thick, with a working area of $5.5 \mathrm{~cm}^{2}$. Potentiodynamic polarization curves $(1 \mathrm{mV} / \mathrm{s})$ were recorded in the range from -0.8 to $-0.3 \mathrm{~V}$ using an IPC-Pro-MF potentiostat. The rate of hydrogen penetration into the metal was determined using the electrochemical hydrogen desorption method. The specimen preparation technique and the experimental procedure were reported previously [38]. Electrode potentials are reported $v s$. SHE.

The following background electrolytes were used:

1) citrate buffer with pH $5.5\left(0.08 \mathrm{M} \mathrm{C}_{6} \mathrm{H}_{8} \mathrm{O}_{7}+0.05 \mathrm{M} \mathrm{NaOH}+0.1 \mathrm{M} \mathrm{KCl}\right)$;

2) citrate buffer ( $\mathrm{pH} 5.5)$ additionally containing $1 \mathrm{mM} \mathrm{Na}_{2} \mathrm{~S}$.

The concentration of inhibitors in the working solution was $1 \mathrm{~g} / \mathrm{l}$. Inhibitors were added to the working electrolyte as concentrated solutions in isopropanol or in water. All 
solutions were prepared from reagent grade chemicals and distilled water. The experiments were carried out at room temperature with free access of air.

\section{Results and discussion}

Effect of inhibitors on the rates of iron anodic dissolution and hydrogen penetration into the metal

Figure 1 shows anodic (solid lines) and cathodic (dashed lines) polarization curves on a steel membrane in background solutions (curves 1) and in the presence of various corrosion inhibitors (Table). The free corrosion potentials of steel $\left(E_{\text {cor }}\right)$ in these media and the rates of hydrogen penetration into the metal $\left(i_{\mathrm{p}}\right)$ at $E_{\text {cor }}$ are also listed in the table. Corrosion inhibitors reduce the anodic current both in citrate buffer containing no added sulfide (Figure 1a) and in the sulfide-containing medium (Figure 1b). The cathodic reaction rate in the presence of CIs also decreases, with exception of the solution containing IFKhAN-29-3 (Figure 1a, curve 7). The corrosion potential in CI solutions generally shifts to less negative values, whereas the rate of hydrogen penetration into the metal at $E_{\text {cor }}$ noticeably decreases, including that in the presence of IFKhAN-29-3.

It was previously shown that the effect of the electrolyte components of interest on the steel dissolution rate can be assessed by comparison of anodic current densities $\left(i_{\mathrm{a}}\right)$ in the presence of an additive and in a background electrolyte at $E=-0.4 \mathrm{~V}$. The rates of the anodic process on $X 70$ and $08 \mathrm{kp}$ steels are almost equal at this potential [33], while the effect of the cathodic reaction on the external current in background solutions is insignificant (Figure 1, curves 1). However, in the presence of certain CIs, for example, the AKN inhibitor in "pure" citrate buffer (Figure 1a, curve 2), $E_{\text {cor }}>-0.4 \mathrm{~V}$. In such cases, the $i_{\mathrm{a}}$ value was estimated by extrapolating the linear part of the anodic curve to $E=-0.4 \mathrm{~V}$ (shown by dot-and-dash lines in Figure 1a). The $i_{\mathrm{a}}$ values in background solutions and with addition of some CIs are listed in the Table. The Table also lists the $E_{\mathrm{cor}}, i_{\mathrm{p}}$ and $i_{\mathrm{a}}$ values measured in "pure" citrate buffer with addition of a mixture of Catamin $\mathrm{AB}$ and $\mathrm{AKN}$ (the polarization curves in solutions of these CIs do not differ qualitatively from those obtained in the presence of other CIs and are not shown in Figure 1).

It follows from the data obtained (Figure 1, Table) that all the CIs studied slow down both the anodic dissolution reaction on steel and the process of hydrogen penetration into the metal. The smallest anodic currents in "pure" citrate buffer are observed in the presence of $\mathrm{AKN}$, the $\mathrm{AKN}+$ Catamin $\mathrm{AB}$ mixture (5:1), and IFKhAN-P-8. In the solution with addition of sulfide, the anodic reaction is most strongly hindered by Catamin $A B$, IFKhAN-29-2 and IFKhAN-P-3. The minimum rates of hydrogen penetration into the metal are observed in the presence of IFKhAN-29-2 and IFKhAN-29-3. 

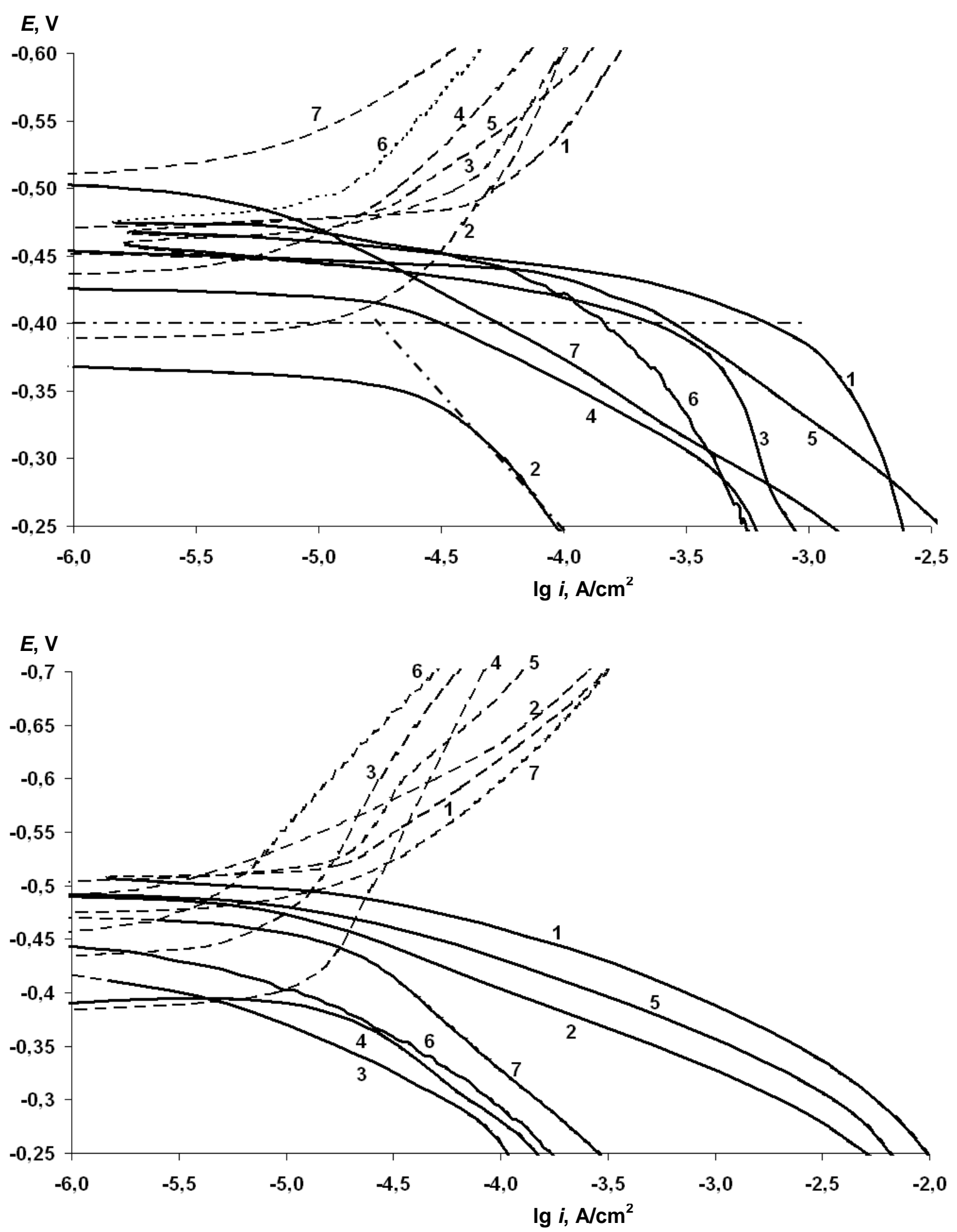

Figure 1. Anodic (solid lines) and cathodic (dashed line) polarization curves on steel in citrate buffer solution (a) and in the same solution with addition of $1 \mathrm{mM} \mathrm{Na}_{2} \mathrm{~S}$ (b). Background solution (1) and with addition of corrosion inhibitors: AKN (2), Catamin AB (3), P-3 (4), I-1 (5), IFKhAN-29-1 (6), IFKhAN-29-2 (7). 
Table. Corrosion potentials $\left(E_{\text {cor }}\right)$, anodic current densities $\left(i_{\mathrm{a}}\right)$ at $E=-0.4 \mathrm{~V}$, current densities of hydrogen penetration into the metal $\left(i_{\mathrm{p}}\right)$ at $E_{\text {cor }}$, stress intensity factors at the crack tip $(K)$, and crack growth rates $(V)$ in pipe steel $\mathrm{X} 70$ in the solutions studied.

\begin{tabular}{|c|c|c|c|c|c|}
\hline Medium & $E_{\text {cor }}, \mathbf{V}$ & $i_{\mathrm{a},}, \mu \mathrm{A} / \mathrm{cm}^{2}$ & $i_{\mathrm{p}}, \mu \mathrm{A} / \mathrm{cm}^{2}$ & $V, \mathbf{m m} / \mathbf{s}$ & $K, \mathrm{MPa} \cdot \mathrm{m}^{0.5}$ \\
\hline Citrate buffer, pH 5.5 & -0.45 & 460 & 13 & $1.64 \mathrm{E}-07$ & 75 \\
\hline$+\mathrm{AKN}$ & -0.38 & 19 & 7 & $5.83 \mathrm{E}-08$ & 65 \\
\hline+ Catamin $\mathrm{AB}$ & -0.46 & 213 & 6.7 & $1.08 \mathrm{E}-07$ & 60 \\
\hline + AKN+Catamin $\mathrm{AB}(5: 1)$ & -0.4 & 8 & 7.7 & $4.44 \mathrm{E}-08$ & 60 \\
\hline + AKN+Catamin AB (1:1) & -0.43 & 25 & 9.7 & $7.50 \mathrm{E}-08$ & 58 \\
\hline + IFKhAN-P-8 & -0.45 & 21 & 6.2 & $7.22 \mathrm{E}-08$ & 46 \\
\hline+ IFKhAN-P-3 & -0.43 & 32 & 6 & $1.94 \mathrm{E}-08$ & 46 \\
\hline$+\mathrm{I}-1$ & -0.46 & & 8 & $1.50 \mathrm{E}-07$ & 52 \\
\hline + IFKhAN-29-1 & -0.46 & 281 & 4 & $6.94 \mathrm{E}-08$ & 62 \\
\hline + IFKhAN-29-2 & -0.51 & 147 & 3 & $8.33 \mathrm{E}-08$ & 48 \\
\hline + IFKhAN-29-3 & -0.43 & 56 & 3 & $5.56 \mathrm{E}-08$ & 55 \\
\hline $\begin{array}{c}\text { Citrate buffer, pH } 5.5+ \\
1 \mathrm{mM} \mathrm{Na}_{2} \mathrm{~S}\end{array}$ & -0.51 & 690 & 17 & $3.44 \mathrm{E}-07$ & 60 \\
\hline$+\mathrm{AKN}$ & -0.49 & 172 & 15 & $2.50 \mathrm{E}-07$ & 63 \\
\hline + Catamin $\mathrm{AB}$ & -0.43 & 3 & 14 & $5.28 \mathrm{E}-08$ & 60 \\
\hline + IFKhAN-P-8 & -0.38 & 59 & 8.7 & $3.33 \mathrm{E}-08$ & 46 \\
\hline + IFKhAN-P-3 & -0.38 & 15 & 7 & $1.39 \mathrm{E}-08$ & 50 \\
\hline$+\mathrm{I}-1$ & -0.495 & & 10 & $1.53 \mathrm{E}-07$ & 47 \\
\hline + IFKhAN-29-1 & -0.46 & 280 & 1.5 & $6.39 \mathrm{E}-08$ & 56 \\
\hline + IFKhAN-29-2 & -0.47 & 13 & 3.7 & $5.56 \mathrm{E}-08$ & 47 \\
\hline+ IFKhAN-29-3 & -0.51 & 55 & 5.6 & $5.28 \mathrm{E}-08$ & 55 \\
\hline
\end{tabular}

Effect of corrosion inhibitors on the corrosion crack growth rate in pipe steel $X 70$

The plots of crack length gain $v s$. time in solutions with addition of CIs are similar to those obtained previously in citrate buffer [39]. The experiment duration ranged from 400 to 700 hours, and the crack increased during an experiment by $0.1-0.3 \mathrm{~mm}$ in "pure" citrate buffer with addition of a CI or by $0.1-0.6 \mathrm{~mm}$ in inhibited sulfide-containing solutions. Such a gain in the crack length allows one to use Eq. (2) in order to calculate the crack growth rate with sufficient reliability, assuming that it remains unchanged during an experiment. The $V$ values thus obtained are listed in the Table, along with the mean $K$ 
values calculated using equation (1) over the entire duration of the experiment. The $K$ values lie in the range from 46 to $80 \mathrm{MPa} \cdot \mathrm{m}^{0.5}$, i.e., they correspond to the plateau region of the kinetic plot of $V v s$. $K$ obtained in citrate buffer $[33,35]$. The deviation of a current $K$ value from the mean value during an experiment generally did not exceed $5 \mathrm{MPa} \cdot \mathrm{m}^{0.5}$.
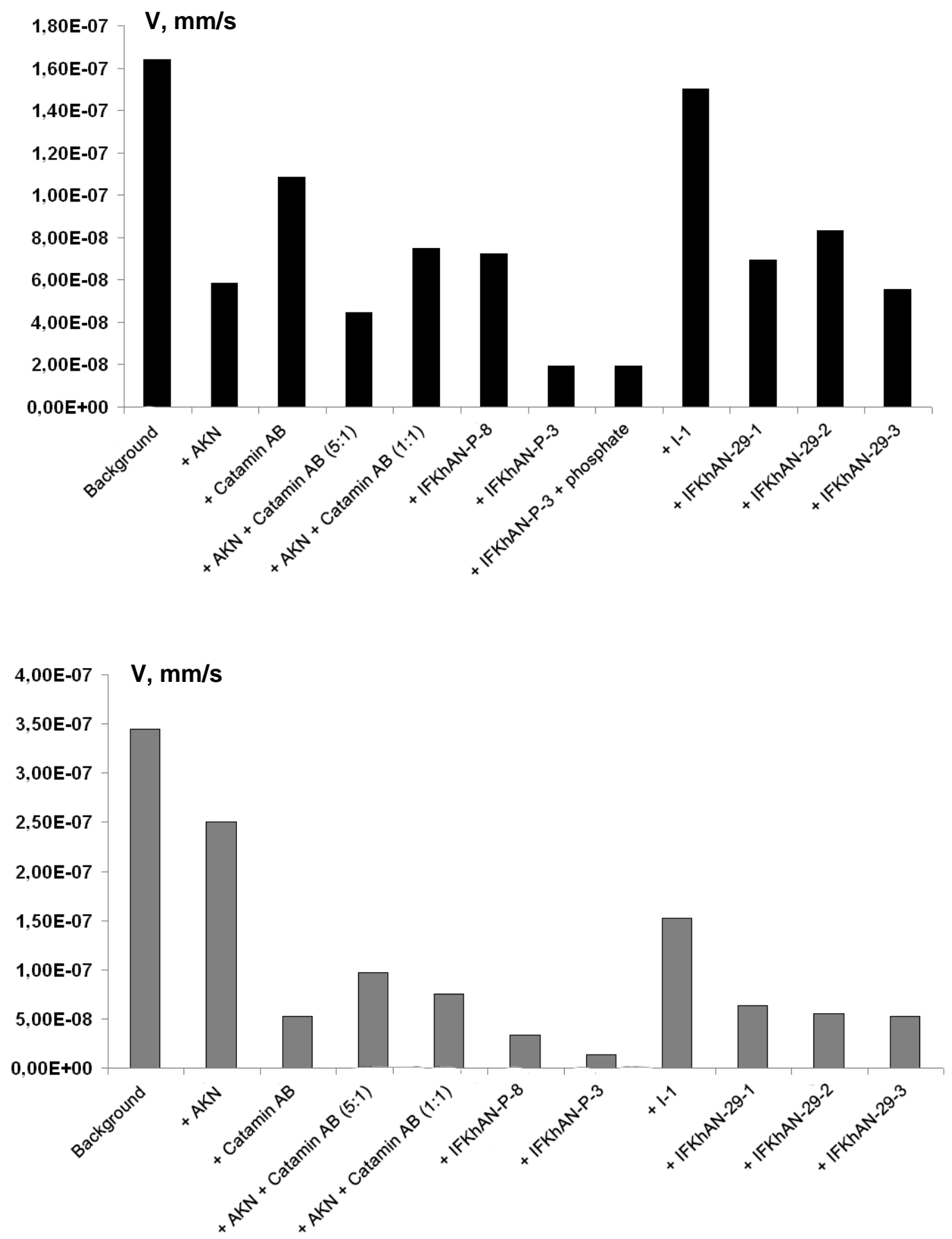

Figure 2. Corrosion crack growth rates in steel X70 in citrate buffer (a) and in the buffer with addition of $1 \mathrm{mM} \mathrm{Na}_{2} \mathrm{~S}$ (b) in the presence of various corrosion inhibitors. 
A graphical comparison of crack growth rates in background solutions and in the presence of various CIs is given in Figure 2. As one can see, the smallest $V$ values in "pure" citrate buffer are observed in the presence of IFKhAN-P-3 and a IFKhAN-P-3 + phosphate $(1 \mathrm{~g} / \mathrm{l})$ mixture (Figure $2 \mathrm{a})$. Both $\mathrm{AKN}$ and its mixture with Catamin $\mathrm{AB}$ have good inhibitive properties in this background solution. The crack growth rate decreases approximately threefold in the presence of $\mathrm{AKN}$. Catamin $\mathrm{AB}$ is a less efficient inhibitor. The crack growth rate decreases 2-3 fold in the presence of IFKhAN-29-1, IFKhAN-29-2 or IFKhAN-29-3. I-1 has almost no effect on the crack growth.

The crack growth in a sulfide-containing solution is two times faster than in "pure" buffer, but the efficiency of CIs in the presence of sulfide is generally higher (Figure $2 b$ ). For example, IFKhAN-P-3 decreases the crack growth rate almost 25-fold, while IFKhAN$\mathrm{P}-8$, tenfold. The crack growth rate is hindered considerably (more than sixfold) by Catamin AB, IFKhAN-29-3, IFKhAN-29-2 and IFKhAN-29-1. AKN and I-1 manifest weaker inhibitive properties.

Thus, like in the case of general corrosion, the ability of organic compounds to hinder the crack growth depends on their chemical nature and the composition of the corrosive medium.

Relationship of the crack growth with the rates of anodic dissolution of steel and hydrogen penetration into steel

Figure 3 shows the variation of $V$ versus $i_{\mathrm{a}}$ and $i_{\mathrm{p}}$ in solutions containing various CIs (Table). As one can see, the crack growth rate well correlates with the anodic current density at $E=-0.4 \mathrm{~V}$ measured in "pure" citrate solution (Figure 3a) and in sulfidecontaining medium (Figure 3c) containing CIs. The correlation coefficients are shown in the Figures. The scatter of points in Figure 3 can be due to objective reasons. To start with, the crack growth should depend on the local dissolution rate of the metal at the crack tip, while the $i_{\mathrm{a}}$ value is calculated per geometric area of the electrode, without consideration for the part of the surface that may be blocked by a deposit of corrosion products, in particular, poorly soluble iron sulfide. This effect may make the $i_{\mathrm{a}}$ values appear smaller than the actual ones, particularly at high iron dissolution rates. Nevertheless, even at small $i_{\mathrm{a}}$ values, it is clear that the plots of $V v s . i_{\mathrm{a}}$ cannot be extrapolated to the origin of coordinates: the crack continues to grow as $i_{\mathrm{a}}$ approaches zero. Perhaps, this is due to the slow adsorption of CI particles on steel. Unlike an electrode used to measure the anodic current densities, the metal at the tip of a growing crack is subject to plastic deformation, hence freshly formed metal surface areas appear continuously and a certain time is required for inhibitor particles to cover this surface. As a result, the rate of metal local dissolution at the crack tip may be much higher than the measured $i_{\mathrm{a}}$ values.

Yet another reason why the crack growth rate differs from zero at $i_{\mathrm{a}} \rightarrow 0$ may be due to the effect of hydrogen absorbed by the metal. However, the correlation between $V$ and $i_{\mathrm{p}}$ is poor (Figure 3b,d), and the existence of this relationship is apparently due to the fact that all the CIs studied slow down not only the anodic dissolution of steel but also the 
penetration of hydrogen into the metal (Table). In the experiments where compounds differently affecting the rates of steel anodic dissolution and hydrogen penetration were added to citrate buffer, no correlation between $V$ and $i_{\mathrm{p}}$ was observed [35].
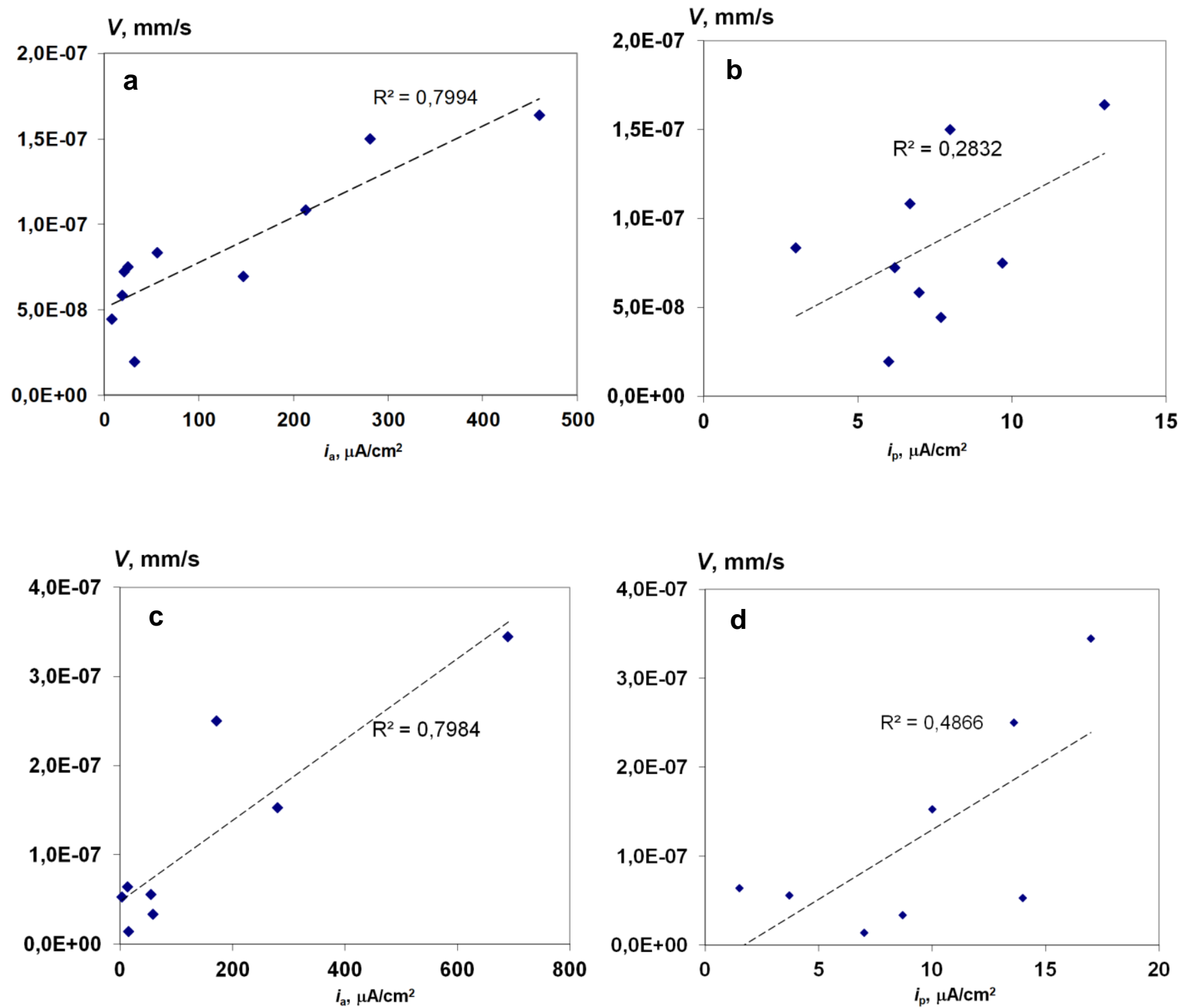

Figure 3. Plots of corrosion crack growth rate in steel X70 vs. anodic current density at a potential of $-0.4 \mathrm{~V}(\mathrm{a}, \mathrm{c})$ and $v s$. the rate of hydrogen penetration into steel $(\mathrm{b}, \mathrm{d})$ in solutions with addition of corrosion inhibitors. Citrate buffer $(a, b)$ and solution with addition of $1 \mathrm{mM}$ $\mathrm{Na}_{2} \mathrm{~S}(\mathrm{c}, \mathrm{d})$.

Thus, local anodic dissolution of the metal is the predominant mechanism of crack growth in pipe steel X70 in citrate buffer solution with addition of organic corrosion inhibitors. 


\section{Conclusions}

1. Organic corrosion inhibitors can considerably slow down the corrosion crack growth in pipe steel X70 under static mechanical strain in citrate buffer ( $\mathrm{pH}$ 5.5) simulating a weakly acidic soil electrolyte. In solutions containing no sulfide ions, the best protective properties are shown by IFKhAN-P-3 inhibitor (based on a salt of polyoxometalates with amines) and a mixture of this inhibitor with phosphate. In the presence of sulfide ions, the best SCC inhibitors for pipe steel include IFKhAN-P-3 and IFKhAN-P-8 formulations, as well as modifications of IFKhAN-29 inhibitor (IFKhAN-29-2 and IFKhAN-29-3) and the quaternary ammonium compound Catamin AB.

2. Good correlation is observed between the corrosion crack growth rate and the anodic dissolution rate of mild steel in weakly acidic electrolytes containing corrosion inhibitors. Hence, the predominant mechanism of crack growth in pipe steel in the weakly acidic electrolytes studied involves local metal dissolution, while the ability of organic compounds to inhibit SCC can be estimated from the anodic current density at a constant potential selected in the region of active dissolution of mild steel.

\section{References}

1. A.I. Malkin, A.I. Marshakov and A.B. Arabei, Korroz.: mater., zashch., 2009, no. 10, 1 (in Russian).

2. A.I. Malkin, A.I. Marshakov, V.E. Ignatenko and A.B. Arabei, Korroz.: mater., zashch., 2010, no. 2, 1 (in Russian).

3. Public Inquiry Concerning Stress Corrosion Cracking on Canadian Oil and Gas Pipeline Steels, Report of NEB, MH-2-95, 1996, 147 pp.

4. A.B. Arabei and Z. Knoshinski, Stress corrosion cracking of main gas pipelines. Charts, Moscow, Nauka, 2006, 106 pp. (in Russian).

5. M. Baker, Department of Transportation. Office of Pipeline Safety. OPS TTO8 Integrity Management Program. Stress corrosion cracking study. Final report, 2005.

6. S.V. Alimov, A.B. Arabei, I.V. Ryakhovskikh, T.S. Esiev, S.V. Nefedov et al., Concept of diagnostics and repair of main gas pipelines in regions with high susceptibility to stress corrosion, Gazovaya promyshlennost', Special issue, 2015, no. 724, 10-15 (in Russian).

7. H.H. Uhlig and R.W. Revie, Corrosion and Corrosion Control. An Introduction to Corrosion Science and Engineering, $3^{\text {rd }}$ Edition, Wiley-Interscience, New York, 1985.

8. Inhibitory corrosion protection of field facilities and pipelines. Basic requirements, Gazprom Company standard 9.3-011-2011, Moscow, 2011, 34 pp. (in Russian).

9. R.N Parkins, Proc. $4^{\text {th }}$ Eur. Symp. Corros. Inhibitors, V. 3, 1975, Ferrara (Italy), 595605.

10. R.N. Parkins, Brit. Corros. J., 1986, 21, no. 1, 1-10.

11. W.-Y. Chu, T.-H. Liu, C.-M. Hsiao and S.-Q. Li, Corrosion, 1981, 37, no. 6, 320-327.

12. M.J. Humphries and R.N. Parkins, Corros. Sci., 1967, 7, no. 11, 747-761. 
13. J. Jaberi, Brit. Corros. J., 1985, 20, no. 3, 133-138. doi: $\underline{10.1179 / 000705985798272812}$ 14. V.V. Savchenkova, F.F. Azhogin, V.V. Chebatarevskii, A.A. Mikheev and A.I. Altsybeeva, Zashch. met., 1985, 21, no. 5, 831-833 (in Russian).

15. C. Alonco, J. Fullea and C. Andrade, J. Corros. Sci. Eng., 2003, 6, Paper C004.

16. L.V. Ratych and I.M. Slobodyan, Fiziko-khim. mekhanika materialov, 1986, 22, no. 6 , 68-75 (in Russian).

17. L.V. Ratych and I.M. Slobodyan, Zashch. met., 1989, 25, no. 5, 723-728 (in Russian).

18. C. Lemaitre, L. Miroud and G. Berange, Proc. $6^{\text {th }}$ Eur. Symp. Corros. Inhibitors, V. 1, 1985, Ferrara (Italy), 668-701.

19. V.P. Solodkina and N.G. Martynova, Fiziko-khim. mekh. mater., 1975, 11, no. 4, 106107 (in Russian).

20. G. Pluvinagt and G. Scherrer, Ann. Chim., 1982, 7, no. 4, 251-268.

21. A.M. Sokurenko, T.Kh. Chen and V.P. Barannik, Zashch. met., 1988, 25, no. 5, $723-$ 728 (in Russian).

22. A. Husain, K. Habib and R. Jarman, Proc. $7^{\text {th }}$ Eur. Symp. Corros. Inhibitors, V. 1, 1990, Ferrara (Italy), 621-628.

23. Yu.I. Babei, A.V. Kapinos and D.M. Zaverobnyi, in: Advances. Methods and means for the protection of metal items from corrosion, Abstracts of All-Union scientific and technical conference, Pt. 3, 1988, Moscow, 41-42 (in Russian).

24. B.P. Luigi, Proc. $6^{\text {th }}$ Eur. Congr. Metal. Corros., London, 1977, 539-545.

25. V.I. Mikhailov, V.F. Belova and N.S. Rodionov, in: Physicochemical studies of inorganic compounds, 1983, Cheboksary, pp. 30-33 (in Russian).

26. V.G. Skvortsov, G.I. Yakhvarov, V.I. Mikhailov, N.S. Rodionov and V.F. Belova, Zashch. met., 1986, 21, no. 1, 161-164 (in Russian).

27. E.S. Ivanov, Corrosion inhibitors for metals in acidic media, Reference book, 1986, Moscow, Metallurgiya, 175 pp. (in Russian).

28. L.V. Frolova, E.V. Tomina, L.P. Kazansky and Yu.I. Kuznetsov, Korroz.: mater., zashch., 2007, no. 7, 22-27 (in Russian).

29. V.E. Ignatenko, Yu.I. Kuznetsov, A.B. Arabei, R.V. Igoshin, R.I. Bogdanov and A.I. Marshakov, Korroz.: mater., zashch., 2011, no. 9, 16-25 (in Russian).

30. I.L. Rozenfel'd, Ingibitory korrozii (Corrosion inhibitors), 1977, Moscow, Khimiya, 350 pp. (in Russian).

31. D.L. Rakhmankulov， D.E. Bugai， A.I. Gabitov， V.M. Golubev， A.B. Laptev and A.A. Kalimullin, Corrosion inhibitors. 1, Ufa, Gos. NTI "Reaktiv", 1997, 296 pp. (in Russian).

32. GOST 9.014-78, Temporary corrosion protection of goods, Standartinform, 2005 (in Russian).

33. A.B. Arabey, R.I. Bogdanov, V.E. Ignatenko, A. Nenasheva and A.I. Marshakov, Prot. Met. Phys. Chem. Surf., 2011, 47, no. 2, 236-245. doi: 10.1134/S2070205111020031

34. V.E. Ignatenko, A.I. Marshakov, V.A. Marichev, Yu.N. Mikhailovskii and N.A. Petrov, Prot. Met., 2000, 36, no. 2, 111-117. doi: 10.1007/BF02758332 
35. A.I. Marshakov, V.E. Ignatenko, R.I. Bogdanov and A.B. Arabey, Effect of electrolyte composition on crack growth rate in pipeline steel, Corros. Sci., 2014, 83, 209-216.

36. Fracture mechanics and strength of materials, Reference book, Ed. V.V. Panasyuk, Kiev, Naukova dumka, 1990, V. 4, p. 680 (in Russian).

37. M.A.V. Devanathan and Z. Stachurski, J. Electrochem. Soc., 1964, 111, no. 5, 619.

38. A.I. Marshakov, O.V. Batishcheva and Yu.N. Mikhailovskii, Prot. Met., 1989, 25, no. 6, $713-720$.

39. R.I. Bogdanov, A.I. Marshakov and V.E. Ignatenko, Korroz.: mater., zashch., 2011, no. 11, 30-37 (in Russian). 